\title{
Physical Chemistry of the $\mathrm{Mn} / \mathrm{ZnO}(000 \overline{1})$ Interface Probed by Hard $\mathrm{X}$-ray Photoelectron Spectroscopy
}

\author{
Mac C. Mugumaoderha, ${ }^{*}$ Robert Sporken, Jacques Ghijsen, and Jacques A. Dumont \\ Research Centre in Physics of Matter and Radiation, University of Namur (FUNDP), Rue de Bruxelles 61, B-5000 Namur, Belgium
}

ABSTRACT: The oxidation of a thin $\mathrm{Mn}$ film grown on a $\mathrm{ZnO}$ $(000 \overline{1})$ surface and the subsequent diffusion of $\mathrm{Mn}$ into the oxide single crystal are investigated in situ by using high-energy $\mathrm{X}$-ray photoelectron spectroscopy (HAXPES). Using hard $\mathrm{X}$-rays allows one not only to investigate the chemistry at the heterojunction but also to describe in detail the thermal diffusion process and the electron energy band alignment at the $\mathrm{Mn} / \mathrm{ZnO}$ interface. Charge transfer occurs between the metallic $\mathrm{Mn}$ film and the $\mathrm{ZnO}$ surface which causes the $\mathrm{ZnO}$ valence band to bend downward in the interfacial region.

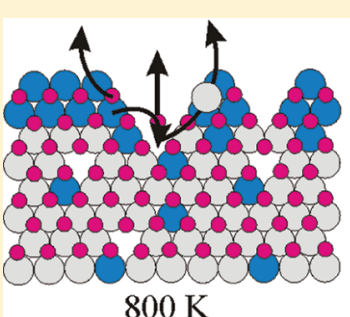

$800 \mathrm{~K}$

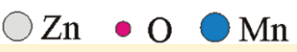

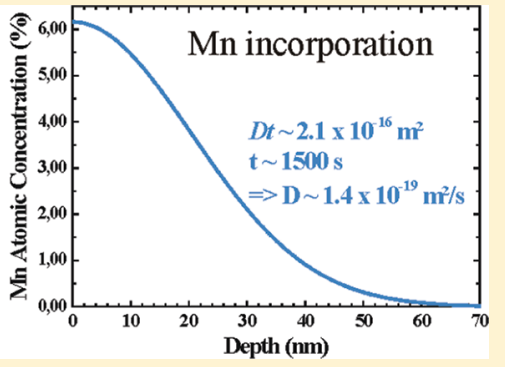

Annealing at $630 \mathrm{~K}$ leads to the formation of a thin two-dimensional $\mathrm{MnO}$ film which induces an upward bending of $\mathrm{ZnO}$ bands. Upon annealing at $800 \mathrm{~K}, \mathrm{Mn}$ diffuses into the substrate crystal. A Mn concentration profile is derived, and a diffusion coefficient of $1.4 \times 10^{-19} \mathrm{~m}^{2} / \mathrm{s}$ is experimentally determined.

\section{INTRODUCTION}

Physical and chemical processes occurring at buried heterojunctions are a major issue of today's electronics. The nanometric downscaling of devices gives a new, unrivaled significance to interfacial processes regarding the efficiency of modern technologies. Buried interfaces are traditionally probed by destructive techniques such as depth profiling which can involve several artifacts such as preferential sputtering, sputter-induced segregation, ion implantation, or activation of interfacial reactions. New methods and means that allow probing buried interfacial processes while limiting sample damage induced by the measurement itself are now available. High-energy X-ray based techniques ${ }^{1}$ and in particular bulk-sensitive hard X-ray photoelectron spectroscopy ${ }^{2}$ are perfectly suited for such a task. In the present work, high-energy $\mathrm{X}$-ray photoelectron spectroscopy (HAXPES) was used to probe interfacial reactions at the $\mathrm{Mn} / \mathrm{ZnO}$ interface upon annealing.

Zinc oxide is a wide band gap oxide used in various industrial applications (as catalytic material, whitener, UV absorber) but is also a promising material for new technologies: the presence of a two-dimensional electron gas at $\mathrm{ZnO} / \mathrm{ZnMgO}$ interfaces can be essential for future high-speed oxide electronics while (Zn,TM)O diluted magnetic oxides (DMOs), where TM is a transition metal, could be used as spin electrodes for roomtemperature spintronic applications. ${ }^{3,4}$ Achieving perfect control of the structure of these $\mathrm{ZnO}$ based ternary compounds is mandatory to establish the desired physical properties. A wide diversity of magnetic properties have been reported in the literature for $(\mathrm{Zn}, \mathrm{TM}) \mathrm{O}$, indicating that the magnetization in such DMOs depends on the growth and doping conditions. Preparing structurally well-ordered ternary compounds still poses a challenge to the point that the experimental parameters and associated physical properties such as the magnetization of DMOs can hardly be reproduced by different groups. ${ }^{5-7}$
In the present work, we focus on the $(\mathrm{Zn}, \mathrm{Mn}) \mathrm{O}$ system. In order to understand the interaction between $\mathrm{Mn}$ and the $\mathrm{ZnO}$ host lattice, a not much reported route consists of studying the physics of the $\mathrm{Mn} / \mathrm{ZnO}$ interface upon annealing. Using synchrotron radiation photoelectron spectroscopy, Zou et al. ${ }^{8}$ and Guziewicz et al. ${ }^{9}$ studied the electronic properties of $\mathrm{Mn} / \mathrm{ZnO}(000 \overline{1})$ upon annealing. Zou et al. found that after annealing at a temperature of $\sim 900 \mathrm{~K}$ interfacial reactions lead to $\mathrm{Mn}$ oxides involving $\mathrm{Mn}^{3+}$ or $\mathrm{Mn}^{4+}$. The investigations of Guziewicz et al. focused on the contribution of $\mathrm{Mn} 3 \mathrm{~d}$ states to the valence band of $\mathrm{ZnMnO}$.

\section{EXPERIMENTAL METHODS}

The $(000 \overline{1})$ O-terminated faces of $\mathrm{ZnO}$ single crystals produced by hydrothermal growth were polished by a mechanical and chemical method (NovaSiC). The samples were then cleaned for $10 \mathrm{~min}$ in an acetone ultrasonic bath and blown dry with nitrogen after the bath.

Next, they were loaded into ultrahigh-vacuum (UHV, base pressure below $2 \times 10^{-9} \mathrm{hPa}$ ) at the beamline BW2 at DESY and cleaned in situ by several $\mathrm{Ar}^{+}$sputtering ( $\left.1 \mathrm{keV}, 5 \mathrm{~min}\right)$ and annealing $(875 \mathrm{~K}, 30 \mathrm{~min})$ cycles until no contaminants were seen by HAXPES and a sharp low energy electron spectroscopy (LEED) pattern of the unreconstructed surface was observed. The samples were heated by direct current flow across a glassy carbon plate in contact with the single crystal. The temperature was calibrated using a type- $\mathrm{K}$ thermocouple in contact with the $\mathrm{ZnO}$ surface before cleaning and $\mathrm{Mn}$ deposition. $\mathrm{Mn}$ was sublimated from a resistively heated filament coiled around a Mn pellet (99.999\% purity) and with the samples very near room

Received: July 12, 2011

Revised: September 14, 2011

Published: September 14, 2011 

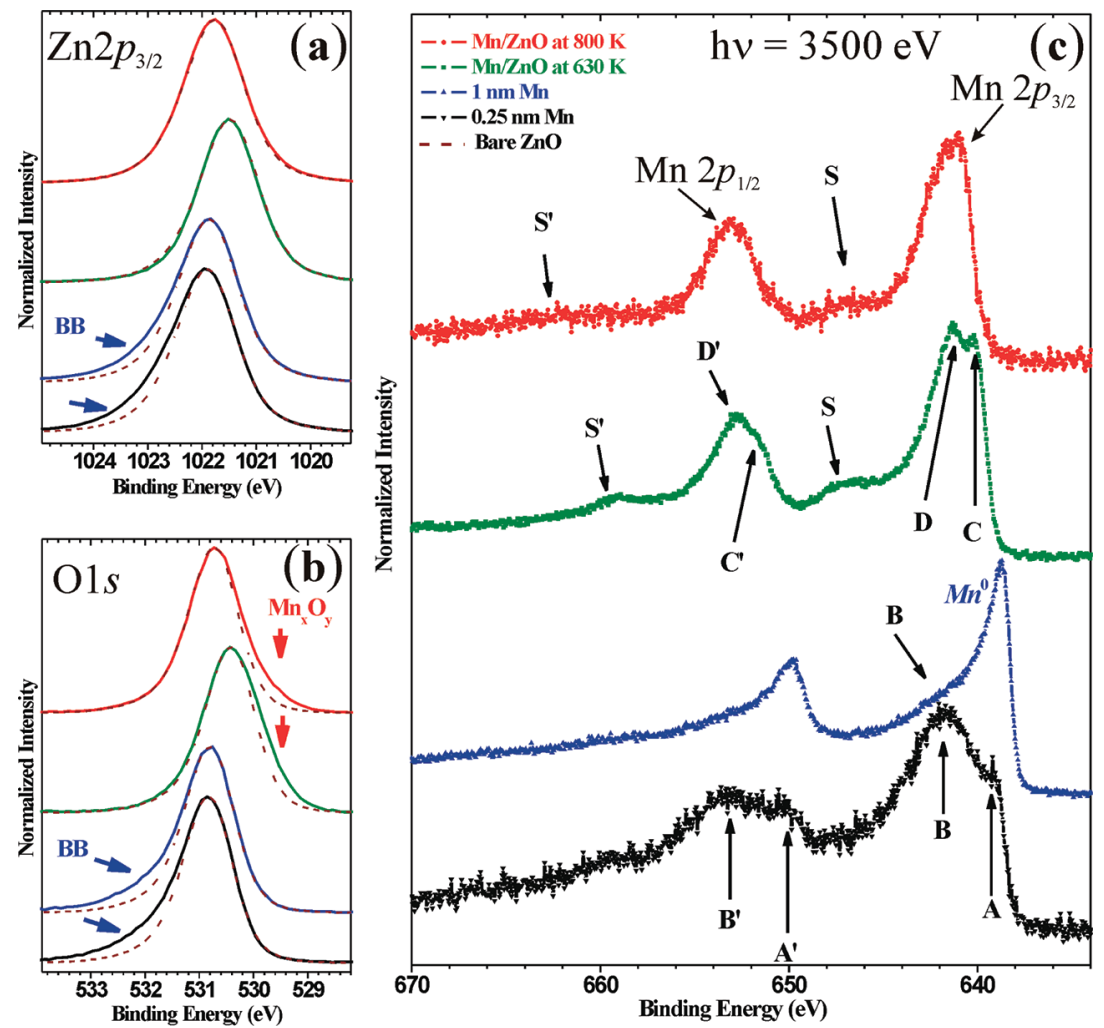

Figure 1. (a) $\mathrm{Zn} 2 \mathrm{p}_{3 / 2}$, (b) O 1s, and (c) Mn 2p photoelectron spectra at different stages of the experiment: bare $\mathrm{ZnO}, 0.25 \mathrm{~nm} \mathrm{Mn}$ deposition, $1 \mathrm{~nm}$ Mn deposition, and annealing at 630 and $800 \mathrm{~K}$. Dotted lines are the bulk $\mathrm{ZnO}$ related spectra plotted for comparison. Labels and arrows are explained in detail in the text.

temperature (exposed to the radiative heat from the evaporator during $3 \mathrm{~min}$ of $\mathrm{Mn}$ deposition). The deposition rate measured using a quartz oscillator before each $\mathrm{Mn}$ growth ranged between 0.125 and $0.25 \mathrm{~nm} / \mathrm{min}$. Mn coverage is specified as equivalent thickness, that is, the thickness of a uniform layer of bulk Mn with the same mass. HAXPES spectra were recorded at a photon energy of $3500 \mathrm{eV}$ with a total energy resolution of $0.5 \mathrm{eV}$. Photoelectrons were collected in the normal emission geometry at an angle of $45^{\circ}$ with respect to the polarization direction of the beam. The electron binding-energy scale was calibrated relative to the $4 \mathrm{f}$ signal of a gold reference sample. The intensity of the $\mathrm{Au} 4 \mathrm{f}_{7 / 2}$ reference spectra was also used to normalize the spectra to the incident photon flux.

\section{RESULTS}

3.1. Spectral Features. Figure 1 shows the $\mathrm{Zn} 2 \mathrm{p}, \mathrm{O} 1 \mathrm{~s}$, and $\mathrm{Mn} \mathrm{2p}$ photoelectron spectra of the $\mathrm{Mn} / \mathrm{ZnO}(000 \overline{1})$ system recorded at different stages of the experiment, which shall be discussed in the following sections.

Mn Deposition at Room Temperature. Both $\mathrm{Zn} \mathrm{2p}$ and $\mathrm{O}$ 1s peaks broaden asymmetrically (see feature $\mathrm{BB}$ at the high binding energy side in Figure 1) after deposition of $\mathrm{Mn}$, which is attributed to the downward bending of the $\mathrm{ZnO}$ band structure close to the interface. Band bending at a metal/semiconductor heterojunction is a common feature caused by work function mismatch between the two materials. In the present case, electron transfer from $\mathrm{Mn}$ to $\mathrm{ZnO}$ is expected because $\mathrm{Mn}$ has a lower work function than $\mathrm{ZnO}(\mathrm{Mn}: 4.1 \mathrm{eV}$ vs $\mathrm{ZnO}$ : 4.1-5.3 $\mathrm{eV}^{10-12}$ ). The signature of band bending in conventional X-ray photoelectron spectroscopy (XPS) usually consists of a rigid shift of the spectral lines from the semiconductor. In the present case, band bending results in an asymmetry in the semiconductor related line shapes. This is due to the much longer electron escape depth when using high energy X-rays: for example, in the case of $\mathrm{O} 1 \mathrm{~s}$, the inelastic mean free path (IMFP) is $4.6 \mathrm{~nm}$ when using $h v=3500 \mathrm{eV}$ and is reduced to $1.9 \mathrm{~nm}$ when using a typical $\mathrm{Al} \mathrm{K} \alpha \mathrm{X}$-ray source $(h v=1486 \mathrm{eV})$. In addition, the depletion region in wide band gap semiconductors can be strongly confined to the surface. As a result, although band bending occurs, photoemission spectra from the semiconductor can still be dominated by the bulk feature, as was shown by Sumiya et al. who studied GaN using a photon energy of $5.95 \mathrm{keV} .^{13}$

The charge transfer between $\mathrm{Mn}$ and $\mathrm{ZnO}$ is confirmed by the shape of the Mn $2 p$ lines at the earliest stages of the experiment. Indeed, upon deposition of $0.25 \mathrm{~nm} \mathrm{Mn}$, the Mn 2p spectrum reflects the superposition of two distinct contributions referred to as $\mathrm{A}$ and $\mathrm{B}$ in the spectrum. Components $\mathrm{A}$ and $\mathrm{A}^{\prime}$ are the low binding energy contributions to $M n 2 p_{3 / 2}$ and $M n 2 p_{1 / 2}$ signals and are related to metallic $\mathrm{Mn}$, whereas components $\mathrm{B}$ and $\mathrm{B}^{\prime}$, at higher binding energy, indicate an electron transfer from $\mathrm{Mn}$ to the $\mathrm{ZnO}$. This electron transfer is directly in relation with the downward bending of the $\mathrm{ZnO}$ bands mentioned above. When the Mn layer thickness is increased to $1 \mathrm{~nm}$, the $\mathrm{Mn} 2 \mathrm{p}$ line shape is closer to that from metallic Mn. Nonetheless, the signal coming from the interfacial Mn layer (satellite B) remains visible.

Annealing Experiments. Annealing removes the asymmetric broadening at the high binding energy side for both the $\mathrm{Zn} 2 \mathrm{p}$ and $\mathrm{O} 1 \mathrm{~s}$ lines, which are both shifted to a lower binding energy. These changes are again associated to band bending and explained in detail in section 3.3. In addition, a new feature 
appears at the low binding energy side of the $O 1$ s line; which is attributed to the formation of manganese oxide. According to Oku et al., ${ }^{14}$ the photoemission spectral features of most $\mathrm{Mn}_{x} \mathrm{O}_{y}$ compounds should appear close to $529.6 \mathrm{eV}$. Thus, the stoichiometry of $\mathrm{Mn}_{x} \mathrm{O}_{y}$ cannot be elucidated based on the $\mathrm{O}$ 1s line shape alone.

Upon annealing the $\mathrm{Mn} / \mathrm{ZnO}$ system at $630 \mathrm{~K}$ for $25 \mathrm{~min}, \mathrm{Mn}$ is fully oxidized. Indeed, the main lines of Mn $2 \mathrm{p}$ shift to higher binding energy and satellites indicated by $S$ and $S^{\prime}$ in Figure 1 appear at $6.5 \mathrm{eV}$ above them. These satellites are due to the coexistence of multiple final states after electron transfer from $\mathrm{Mn}$ to surrounding $\mathrm{O}$ ligands. In addition, the $\mathrm{Mn} 2 \mathrm{p}_{3 / 2}\left(\mathrm{Mn} 2 \mathrm{p}_{1 / 2}\right)$ main line presents a fine structure showing two peaks $\mathrm{C}$ and $\mathrm{D}\left(\mathrm{C}^{\prime}\right.$ and $\left.\mathrm{D}^{\prime}\right) 1.2 \mathrm{eV}$ apart from each other. Note that feature $\mathrm{D}$ in the $\mathrm{Mn} 2 \mathrm{p}_{3 / 2}$ peak is more intense than feature C. Further annealing to $800 \mathrm{~K}$ led to a slight modification of the Mn 2p line shapes: the fine structure observed in the $\mathrm{Mn} 2 \mathrm{p}_{3 / 2}$ cannot be resolved anymore and the lines become slightly narrower and apparently shifted toward higher binding energy. The overall shape of the Mn $2 p$ spectra obtained after annealing is characteristic of $\mathrm{Mn}^{2+15-20}$ The slight modifications of the Mn $2 \mathrm{p}$ fine structure (C, D, $\mathrm{C}^{\prime}$, and $\mathrm{D}^{\prime}$ ) after the final annealing will be addressed in detail in a separate study involving charge transfer multiplet calculations as well as X-ray absorption near edge structure (XANES) analysis. ${ }^{21}$ In the present system, $\mathrm{Mn}^{2+}$ can be expected inside a rocksalt $\mathrm{MnO}$ segregated phase or in wurtzitic $(\mathrm{Zn}, \mathrm{Mn}) \mathrm{O}$ where $\mathrm{Mn}$ atoms substitute $\mathrm{Zn}$ in the $\mathrm{ZnO}$ lattice, but the conclusions of this separate study suggest that these spectral modifications are related to the existence of traces of additional phases for the annealing steps at the lowest temperature rather than a change in the crystal field symmetry.

3.2. Stoichiometry and Mn Diffusion. Lumping all the technical aspects of a photoemission experiment (geometry of the setup, transmission of the analyzer, photon energy, etc.) together as a constant, the intensity of the photoelectron signal related to a given subshell from a specific element B homogeneously distributed inside a material A follows:

$$
I_{\mathrm{B}, \mathrm{A}} \propto \sigma_{\mathrm{B}} \lambda_{\mathrm{B}, \mathrm{A}} C_{\mathrm{B}, \mathrm{A}}
$$

where $\sigma$ is the photoemission cross section of the subshell, $\lambda$ is IMFP (if elastic scattering effects are neglected ${ }^{22}$ ), and $C$ is the atomic concentration of the specific element in the material. When $\mathrm{B}$ is included into two different materials $\mathrm{A}$ and $\mathrm{C}$, the ratio of the XPS intensity related to the subshell of B into these two materials is given by

$$
\frac{I_{\mathrm{B}, \mathrm{A}}}{I_{\mathrm{B}, \mathrm{C}}}=\frac{\lambda_{\mathrm{B}, \mathrm{A}} C_{\mathrm{B}, \mathrm{A}}}{\lambda_{\mathrm{B}, \mathrm{C}} C_{\mathrm{B}, \mathrm{C}}}
$$

provided experimental conditions are otherwise identical.

This relationship will be used in the following for interpreting variations in the core level intensities of the $\mathrm{Mn} 2 \mathrm{p}, \mathrm{Zn} 3 \mathrm{~s}$, and $\mathrm{O}$ 1s lines with respect to $\mathrm{Mn}$ deposition, oxidation, and diffusion. IMFP values are estimated using the so-called TPP-2 M formula. ${ }^{24}$ The values of all parameters required for the following simulations are summarized in Table 1.

In Figure 2, we show the HAXPES intensity of the Mn 2p, Zn $3 \mathrm{~s}$, and $\mathrm{O} 1 \mathrm{~s}$ lines at various steps of the experiment. The $\mathrm{Zn} 3 \mathrm{~s}$ peak was preferred to $\mathrm{Zn} 2 \mathrm{p}$ as the zinc-related signal, because $\mathrm{Zn}$ $2 p$ was not recorded under the same experimental conditions as $\mathrm{Mn} \mathrm{2p,} \mathrm{Zn} \mathrm{3s}$, and $\mathrm{O}$ 1s (the monochromator slit had to be reduced to compensate for the intensity of the $\mathrm{Zn} 2 \mathrm{p}$ line). The HAXPES intensity is normalized to the intensity of the incident
Table 1. Parameters Used for Calculating the IMFP $\lambda$ in Three Materials

\begin{tabular}{llll} 
& \multicolumn{1}{c}{$\mathrm{ZnO}$} & \multicolumn{1}{c}{$\mathrm{MnO}$} & \multicolumn{1}{c}{$\mathrm{Mn}$} \\
lattice Structure & wurtzite & wurtzite & cubic \\
$a(\mathrm{~nm})$ & 0.325 & 0.3314 & 8.91 \\
$c(\mathrm{~nm})$ & 0.521 & 0.5412 & \\
density $\left(\mathrm{kg} / \mathrm{m}^{3}\right)$ & 5.606 & 4.588 & 7.470 \\
molar mass $(\mathrm{kg} / \mathrm{mol})$ & $81.389 \times 10^{-3}$ & $70.938 \times 10^{-3}$ & $54.938 \times 10^{-3}$ \\
band gap $(\mathrm{eV})$ & 3.4 & $3.6^{b}$ & \\
$N_{\mathrm{v}}{ }^{b}$ & 18 & 13 & 7 \\
$C_{\mathrm{Mn}, \mathrm{XO}}(z, t)[\mathrm{Mn}$ or $\mathrm{Zn}]$ & $4.14 \times 10^{28}$ & $3.89 \times 10^{28}$ & $8.19 \times 10^{28}$ \\
$\quad\left(\right.$ atoms $\left./ \mathrm{m}^{3}\right)$ & & & \\
$\lambda_{\mathrm{Mn} 2 \mathrm{p}, 2859 \mathrm{eV}}(\mathrm{nm})$ & 4.702 & 4.556 & 3.821 \\
$\lambda_{\mathrm{Zn3s}, 3362 \mathrm{ev}}(\mathrm{nm})$ & 5.198 & 5.367 & 4.356 \\
\hline
\end{tabular}

${ }^{a} \mathrm{~N}_{\mathrm{v}}$ is the number of valence electron per $\mathrm{ZnO}$ or $\mathrm{MnO}$ molecule, required for the TPP-2M formula. ${ }^{24 b}$ The band gap of wurtzite $\mathrm{MnO}$ is not known. Therefore, we used the value from rocksalt $\mathrm{MnO}^{23}$

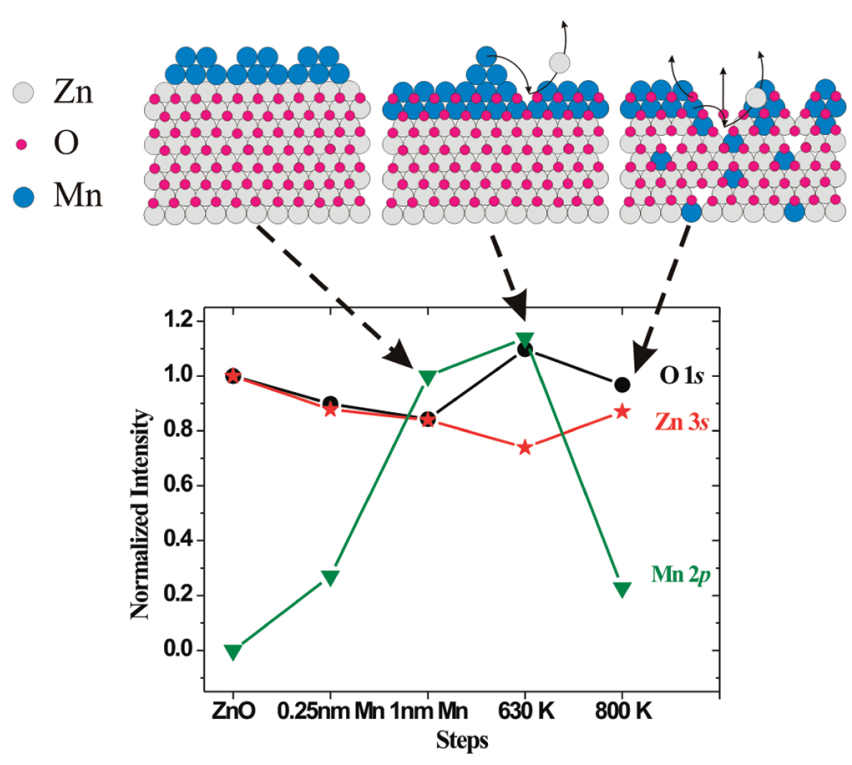

Figure 2. Integrated HAXPES intensity of the Mn $2 p, \mathrm{Zn} 3 \mathrm{~s}$, and $\mathrm{O} 1 \mathrm{~s}$ lines at the successive steps of the experiment: bare $\mathrm{ZnO}$ surface, $\mathrm{Mn}$ deposition (two steps: $0.25 \mathrm{~nm}$ and additional $0.75 \mathrm{~nm}$ ), and two annealing steps (at 630 and $800 \mathrm{~K}, 25 \mathrm{~min}$ each step). Drawings are added to the graph in order to illustrate the physicochemical phenomena reported at each step and described in detail in the text.

beam and the data acquisition time. The Mn $2 \mathrm{p}$ signal was recorded from the $1 \mathrm{~nm}$ as-grown $\mathrm{Mn}$ coverage and the $\mathrm{Zn} 3 \mathrm{~s}$ and $\mathrm{O} 1 \mathrm{~s}$ signal intensities from the clean $\mathrm{ZnO}$ surface are set to unity.

As seen in Figure 2, both the $\mathrm{O} 1 \mathrm{~s}$ and $\mathrm{Zn} \mathrm{3s}$ signals are attenuated upon Mn deposition (in two steps). The intensity $I_{0, \mathrm{~A}}$ of XPES signals from a bulk material $\mathrm{A}$ is attenuated by a layer of material $\mathrm{B}$ of thickness $d$ so that the recorded intensity becomes

$$
I_{\mathrm{A}}=I_{0, \mathrm{~A}} \mathrm{e}^{-d / \lambda_{\mathrm{B}}}
$$

The attenuation of these signals can therefore be used to verify the thickness $d_{\mathrm{Mn}}$ of the deposited Mn. A thickness $d_{\mathrm{Mn}}$ of $0.8 \mathrm{~nm}$ was calculated based on the attenuation of the $\mathrm{Zn} 3 \mathrm{~s}$ signal. This value is slightly smaller than the value of $1 \mathrm{~nm}$ estimated using the 
quartz thickness monitor but constitutes the lower limit of the amount of Mn deposited. Indeed this calculation is based on the hypothesis that the $\mathrm{Mn}$ film is growing layer by layer, that is, two-dimensionally. A larger $\mathrm{Mn}$ amount is required to achieve the same attenuation if the film is instead growing three-dimensionally, which is very likely the case according to the literature. ${ }^{25}$

At $630 \mathrm{~K}$, we observed an increase in the intensity of the oxygen peak with respect to the zinc. From Figure 1, it is seen that these phenomena occur simultaneously with $\mathrm{Mn}$ oxidation. We can thus conclude that $\mathrm{Mn}$ oxidation proceeds via $\mathrm{Zn}$ substitution, with the substituted zinc being sublimated. The vapor pressure of elemental $\mathrm{Zn}$ is indeed very high at this temperature $\left(P_{\text {vap, } \mathrm{Zn}}^{630 \mathrm{~K}} \sim 1 \times 10^{-2} \mathrm{mbar}\right)$. Again, the thickness of the $\mathrm{MnO}$ film can be estimated from the attenuation of the $\mathrm{Zn} 3 \mathrm{~s}$ signal. A value of $d_{\mathrm{MnO}} \sim 1.6 \mathrm{~nm}$ was calculated from eq 3 . Owing to the respective structural properties of the wurtzite $\mathrm{MnO}$ layer and the as-grown $\mathrm{Mn}$ film, these values $d_{\mathrm{MnO}}$ and $d_{\mathrm{Mn}}$ correspond to the same area density of $6.6 \times 10^{19} \mathrm{Mn}$ atoms $/ \mathrm{m}^{2}$. This estimate is based on the assumption that the $\mathrm{MnO}$ layer is formed by $\mathrm{Zn}$ substitution. Hence, the wurtzite structure of $\mathrm{ZnO}$ was imposed on $\mathrm{MnO}$ which usually appears in rocksalt (rs) structure. The structural parameters of wurtzite $\mathrm{MnO}$ are very close to those from $\mathrm{ZnO}$ and were taken from Schrön et al. ${ }^{26}$

The increase in intensity of Mn 2p upon oxidation of Mn has probably two origins. First, with XPS being a surface-sensitive technique, the signal emitted from a given amount of material grown as a thin film on a substrate is larger if the structure of the film is two-dimensional (2D) and spreads over the whole substrate area and is smaller if, instead, the film is three-dimensional (3D) and covers a fraction of the surface. As we mentioned earlier, the structure of the metallic Mn layer initially grows as a three-dimensional film while oxidation proceeds via $\mathrm{Zn}$ substitution from a very flat substrate (obtained by MCP polishing; see refs 27 and 28) and leads to the formation of a 2D MnO layer. Thanks to eq 2 and owing to the fact that the XPS intensity from a thin film of thickness $d$ follows

$$
I=I_{0}\left(1-\mathrm{e}^{-d / \lambda}\right)
$$

where $I_{0}$ is the intensity from an infinitely thick layer, we calculated the intensity variation from a $3 \mathrm{D} \mathrm{Mn}$ film and a $2 \mathrm{D}$ $\mathrm{MnO}$ layer. As a matter of fact, we could not reproduce the increase from 1 to 1.14 of the Mn 2p XPS intensity upon annealing at $630 \mathrm{~K}$. Actually, it is highly probable that this variation is also partly due to the difficulty of comparing the area of $\mathrm{Mn} 2 \mathrm{p}$ peaks before and after oxidation. Indeed, the shape of the peak and the background change dramatically between these two steps (see Figure 1), and obtaining an absolute value of the Mn 2p area with an error smaller than $10 \%$ is probably impossible.

Upon annealing at $800 \mathrm{~K}$, the signal from Mn $2 \mathrm{p}$ drops considerably and the $\mathrm{Zn}: \mathrm{O}$ stoichiometry of $1: 1$ is almost restored. According to Kleinlein and Helbig, ${ }^{29} \mathrm{Mn}$ diffuses into the bulk of $\mathrm{ZnO}$, which explains the intensity loss. We exclude reevaporation of $\mathrm{Mn}$ atoms as the heat of formation of manganese oxide (between -350 and $-400 \mathrm{~kJ} / \mathrm{mol}$ ) is smaller than that of $\mathrm{ZnO}(-300$ to $-350 \mathrm{~kJ} / \mathrm{mol}$ ), which means that $\mathrm{MnO}$ is more stable than $\mathrm{ZnO}^{12}$ As seen previously, a $2 \mathrm{D} \mathrm{MnO}$ film is formed on the surface prior to this last annealing step. Hence, diffusion of $\mathrm{Mn}$ deeper into the bulk of $\mathrm{ZnO}$ requires the decomposition of this surface oxide. The excess of $O$ is then released, which partially restores the stoichiometry of $\mathrm{ZnO}$.

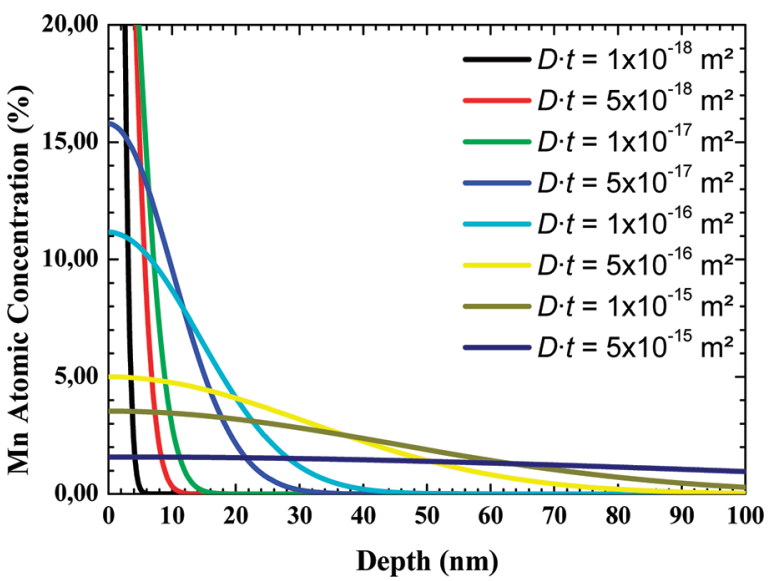

Figure 3. Atomic concentration profiles for $\mathrm{Mn}$ diffusion into $\mathrm{ZnO}$. Calculation based on Fick's second law (eq 5) for various values of $D t$. The initial Mn area density was estimated to be $6.6 \times 10^{19}$ atoms $/ \mathrm{m}^{2}$, and $C_{\mathrm{B}, \mathrm{A}}(z, t)$ was divided by the molecular density of $\mathrm{ZnO}\left(4.14 \times 10^{28}\right.$ molecules $\left./ \mathrm{m}^{3}\right)$ in order to present $C_{\mathrm{B}, \mathrm{A}}(z, t)$ as atomic concentrations.

The diffusion of $\mathrm{Mn}$ from a thin, almost pure 2D MnO film into the bulk of $\mathrm{ZnO}$ can be described by Fick's second law:

$$
C_{\mathrm{B}, \mathrm{A}}(z, t)=\frac{Q}{\sqrt{\pi D t}} \mathrm{e}^{-z^{2} / 4 D t}
$$

where $z$ is the coordinate normal to the surface, $t$ is the annealing/diffusion time, and $D\left(\mathrm{~m}^{2} / \mathrm{s}\right)$ is the temperaturedependent diffusion coefficient for material $\mathrm{B}$ into material $\mathrm{A}$. For the sake of simplicity, we will not separate the various diffusion channels (substitutional diffusion, grain diffusion, etc.). $Q$ is the initial amount (number of atoms $/ \mathrm{m}^{2}$ ) of $\mathrm{Mn}$ in the $2 \mathrm{D}$ $\mathrm{MnO}$ film which was estimated above to be about $6.6 \times 10^{19}$ atoms $/ \mathrm{m}^{2}$. Figure 3 shows such depth profiles calculated for various values of $D t$.

The only unknown parameter in eq 5 is the $\mathrm{Mn}$ diffusion coefficient $D$. In the following, we will estimate $C_{\mathrm{B}, \mathrm{A}}(z, t)$ and hence $D$ from the attenuation of the Mn 2p XPS signal, which is dependent on the distribution profile of the $\mathrm{Mn}$ atoms upon annealing at $800 \mathrm{~K}$. In order to achieve this, we must express $I_{\mathrm{B}, \mathrm{A}}$ as a sum of signals $I_{\mathrm{B}, \mathrm{A}, \Delta z}$ emitted from thin layers of thickness $\Delta z=c / 2(c=0.52 \mathrm{~nm}$ for $\mathrm{ZnO})$ and located at increasing depth with respect to the surface of the material.

$$
I_{\mathrm{B}, \mathrm{A}}=\sum_{n=0}^{\infty}\left[\left(C_{\mathrm{B}, \mathrm{A}}(z, t) I_{\mathrm{B}, \mathrm{A}, \Delta z}(z)\right) \mathrm{e}^{-n \Delta z / \lambda}\right]
$$

with $I_{\mathrm{B}, \mathrm{A}, \Delta z}$ given by eq 4 for a layer of thickness $\Delta z$. Finally, according to eqs 2,4 , and 6 , we can estimate the intensity ratio between the Mn 2p signals prior and after annealing:

$$
\frac{I_{\mathrm{Mn}, \mathrm{ZnO}}}{I_{\mathrm{Mn}, \mathrm{MnO}}}=\frac{\lambda_{\mathrm{ZnO}}}{\lambda_{\mathrm{MnO}}} \frac{\sum_{n=0}^{\infty}\left\{\left[C_{\mathrm{Mn}, \mathrm{ZnO}}(z, t)\left(1-\mathrm{e}^{\Delta z / \lambda_{\mathrm{ZnO}}}\right)\right] \mathrm{e}^{-n \Delta z / \lambda}\right\}}{C_{\mathrm{Mn}, \mathrm{MnO}}\left(1-\mathrm{e}^{d_{\mathrm{MnO}} / \lambda_{\mathrm{MnO}}}\right)}
$$

From the values of $d_{\mathrm{MnO}}$ calculated above and from those of $C_{\mathrm{Mn}, \mathrm{MnO}}(z, t)$ and $\lambda_{\mathrm{MnO}}$ in Table 1 , we can estimate the denominator of eq 7; the numerator is calculated numerically by adding intensities emitted by successive $\mathrm{ZnO}$ double layers $(\Delta z \sim$ $0.26 \mathrm{~nm}$ ) at increasing depth inside the $\mathrm{ZnO}$ single crystal. Figure $4 \mathrm{a}$ shows the results corresponding to the diffusion 

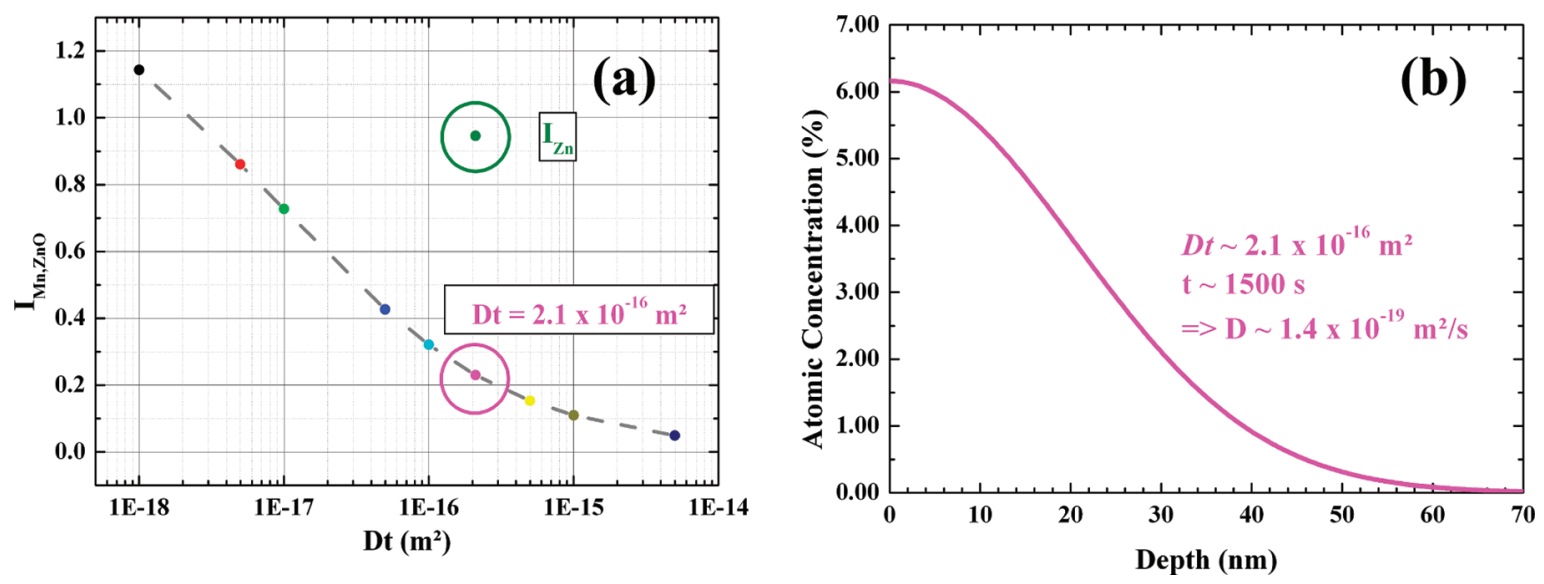

Figure 4. (a) Calculated Mn 2p HAXPES intensity versus $D t$ for the various Mn atomic concentration profiles shown in Figure 3. An additional value was calculated for $D t=2.1 \times 10^{-16} \mathrm{~m}^{2}$, corresponding to the diffusion profile shown in (b) and to an XPS intensity comparable to that measured after annealing at $800 \mathrm{~K}$. The $\mathrm{Zn} 3 \mathrm{~s}$ intensity corresponding to $\mathrm{Dt}=2.1 \times 10^{-16} \mathrm{~m}^{2}$ is also shown in (a); see text for more details.

profiles shown in Figure 3. According to eq 7, the results were multiplied by $I_{\mathrm{Mn}, M n O}(\sim 1.14$, see Figure 2$)$.

The curve in Figure 4a illustrates that a value of $D t$ near $2.1 \times$ $10^{-16} \mathrm{~m}^{2}$ agrees best with to the intensity drop of the Mn $2 \mathrm{p}$ signal from 1.14 to 0.23 upon annealing. From the annealing time, $1500 \mathrm{~s}$, we can deduce that the overall diffusion coefficient of $\mathrm{Mn}$ into $\mathrm{ZnO}$ at $800 \mathrm{~K}$ is approximately $1.4 \times 10^{19} \mathrm{~m}^{2} / \mathrm{s}$. We are not aware of the diffusion coefficient of $\mathrm{Mn}$ into $\mathrm{ZnO}$ in the temperature range around $800 \mathrm{~K}$, and an Arrhenius-type extrapolation of data recorded between 1400 and $1600 \mathrm{~K}$ by Kleinlein and Helbig ${ }^{29}$ results in a value many orders of magnitude below our value of $D$. Nevertheless, a similar conclusion was recently reached by Koskelo et al., ${ }^{30}$ namely that their diffusion coefficients $\mathrm{D}$ for the diffusion of $\mathrm{Co}$ into $\mathrm{ZnO}$ were several orders of magnitude above that from Kleinlein and Helbig. In fact, considering Koskelo et al.'s results, it seems that the diffusion coefficient extracted from our data is of the same order of magnitude as for the substitutional diffusion of other elements such as $\mathrm{Cu}, \mathrm{In}$, and $\mathrm{Co}$ in $\mathrm{ZnO}$. This conclusion is in fair agreement with the fact that, as shown above, $\mathrm{Zn}$ substitution by $\mathrm{Mn}$ proceeds during the oxidation process.

Finally it is also worth mentioning that, as shown in Figure 4a, the intensity of the $\mathrm{Zn} 3 \mathrm{~s}$ signal calculated from the diffusion profile for $D t \sim 2.1 \times 10^{-16} \mathrm{~m}^{2}$ (leading to $I_{\mathrm{Mn}, \mathrm{ZnO}} \sim 0.23$ ) is slightly larger than the experimental value $\left(I_{\mathrm{Mn}, \mathrm{ZnO}} \sim 0.87\right.$, see Figure 2). This can easily be explained by the creation of $\mathrm{Zn}$ vacancies after the diffusion of Mn deeper into the material. This hypothesis is supported by the slight $\mathrm{O}$ excess remaining after the final annealing (Figure 2).

3.3. Band Bending. The bending of electronic bands at semiconductor surfaces or interfaces lies in the respective position of the Fermi level $\left(E_{\mathrm{F}}\right)$ and of the charge neutrality level (CNL). While $E_{\mathrm{F}}$ is mostly determined by doping, the CNL is an intrinsic property of the material related to the presence of a continuum of virtual gap states (VIGS) at semiconductor surfaces or interfaces as a result from the broken bulk symmetry. ${ }^{31}$ In addition, King et al. ${ }^{32}$ have recently shown that the position of the CNL also dictates the electrical behavior of defects and hence coincides with the Fermi level stabilization energy $\left(E_{\mathrm{FS}}\right)$ defined by Walukiewicz in his so-called amphoteric defect model (ADM) level. ${ }^{33}$ Hence, if large amounts of defects or impurities are introduced in a semiconductor, the Fermi level will converge toward the CNL. These two pieces of information are important for understanding the present results.

In the present work, we have access to several data which allow us to describe the alignment of the energy bands at the various stages of the experiment properly. The relative energy shifts of the $\mathrm{Zn}$ and $\mathrm{O}$ core levels from a given experimental step to the other indicate band bending. The leading edge of the valence band indicates the position of the Fermi level within the energy gaps (if any) of the materials. Finally, according to the preceding sections, we know the oxidation states of $\mathrm{Mn}$ and $\mathrm{Zn}$ and we can then refer to the literature regarding the intrinsic properties of the materials such as electroaffinity (for semiconductors) or work function (for metals), band gap, and so forth.

As seen in Figure 5a, the valence band of the bare $\mathrm{ZnO}$ surface is located at $3.4 \mathrm{eV}$ below the Fermi level which coincides with the conduction band minimum (CBM) as illustrated in Figure 5c. This is typical of $\mathrm{ZnO}^{34,35}$ and has its origin in the fact that the $\mathrm{CNL}$ of $\mathrm{ZnO}$ is located $\sim 0.2 \mathrm{eV}$ above the $\mathrm{CBM}^{36}$ and that $\mathrm{ZnO}$ is highly reactive to hydrogen, a very shallow donor impurity of $\mathrm{ZnO} .{ }^{37,38}$ Hence, the inevitable presence of hydrogen lifts the Fermi level close the CNL. If $\mathrm{H}$ is present at the surface only, the energy band must bend downward in the vicinity of the surface. If $\mathrm{H}$ is present deeper in the bulk of the material, the bands should be flat. The presence of hydroxide compounds is not seen in the $\mathrm{O} 1 \mathrm{~s}$ spectra of the bare $\mathrm{ZnO}$ surface (Figure 1) while the $(1 \times 1)$ LEED pattern is typical of a hydrogenated $\mathrm{ZnO}$ $(000 \overline{1})$ surface $^{39}$ This contradiction can be attributed to the poorer surface sensitivity of HAXPES (compared to usual XPS). In addition to the adsorption of $\mathrm{H}$ at the surface, bulk $\mathrm{H}$ might also be present. As explained above, the surface preparation of $\mathrm{ZnO}$ involves annealing at $875 \mathrm{~K}$. At such a temperature, interstitial $\mathrm{H}$ atoms bound to $\mathrm{O}\left(\mathrm{H}_{\mathrm{i}}\right)$ should all be diffused out of the material. Nevertheless, $\mathrm{H}$ might still be present at $\mathrm{O}$ vacancy sites $\left(\mathrm{H}_{\mathrm{O}}\right)$ where it would not be detectable in the $\mathrm{O}$ related XPS lines. Actually, there is still a controversy on the thermal stability of $\mathrm{H}_{\mathrm{O}}$ : while some reports mention the complete desorption of $\mathrm{H}$ from $\mathrm{H}_{\mathrm{O}}$ sites around $800 \mathrm{~K}$ for $\mathrm{H}^{*}$ or ${ }^{2} \mathrm{H}^{*}$ plasma-treated samples, ${ }^{40}$ an activation barrier as high as $1.7 \mathrm{eV}$ was calculated ${ }^{41}$ for the diffusion of $\mathrm{H}_{\mathrm{O}}$ and a strong hydrogen desorption was recorded on $\mathrm{ZnO}$ samples annealed above 1100 $\mathrm{K}^{42,43}$ This all means that, depending on the sample growth conditions, substantial amounts of $\mathrm{H}_{\mathrm{O}}$ may be present in $\mathrm{ZnO}$ 

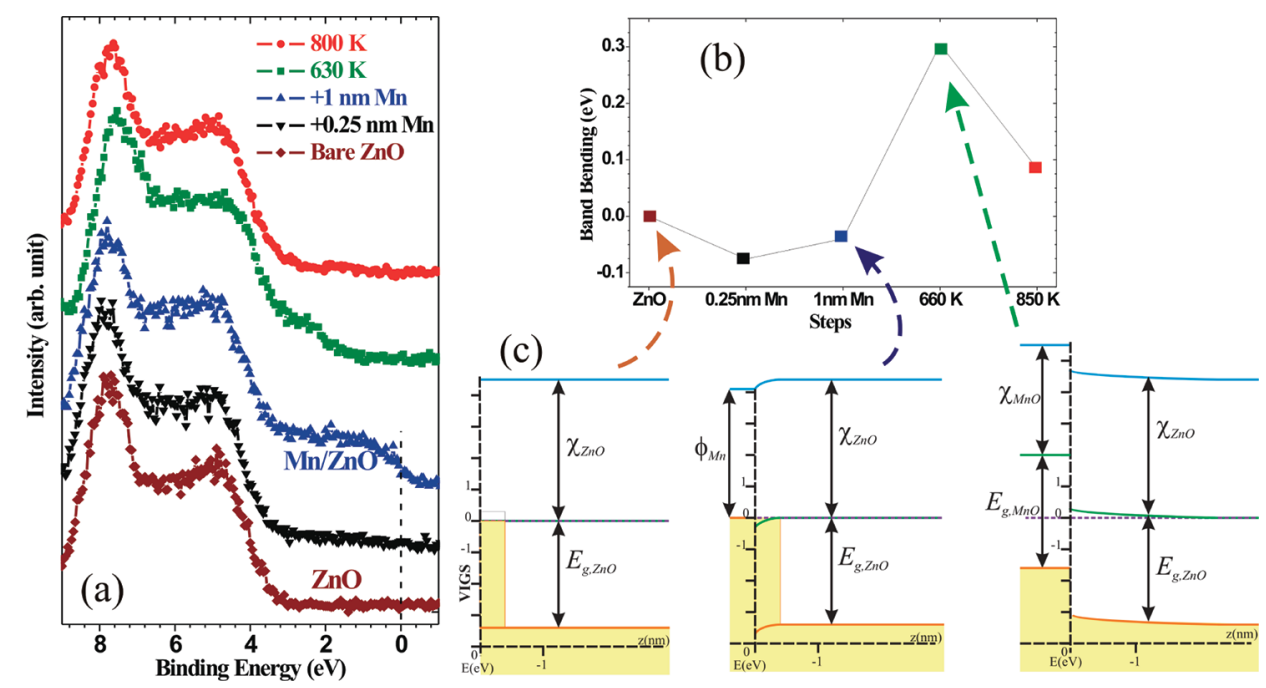

Figure 5. (a) Valence band of $\mathrm{Mn} / \mathrm{ZnO}$ at different stages of the experiment. (b) Band bending measured by the binding energy shifts of $\mathrm{Zn} 2 \mathrm{p}$ with respect to the Fermi level. Negative values correspond to an upward band bending. (c) Energy band alignment after Mn deposition (middle panel) and oxidation (right panel).

and thermally stable even at $875 \mathrm{~K}$, the highest temperature reached during our sample preparation. Hence, we believe that, in the present case, there is a bulk hydrogen contamination and hence a flat band situation (Figure 5c).

A steep downward bending of $\mathrm{ZnO}$ bands is observed upon $\mathrm{Mn}$ deposition (Figure 1). Such band bending is not seen in Figure $5 \mathrm{~b}$ which only refers the displacements of the main $\mathrm{Zn}$ and $\mathrm{O}$ components. Indeed, as said above and pictured in Figure 5c, this band bending is confined at the $\mathrm{Mn} / \mathrm{ZnO}$ interface and the XPES spectra are still dominated by the bulk, non shifted components. The band bending can easily be related to the mismatch between the work function of $\mathrm{Mn}\left(\phi_{\mathrm{Mn}}=4.1 \mathrm{eV}\right.$ for polycrystalline $\left.\mathrm{Mn}\right)$ and the $\mathrm{CNL}$ of $\mathrm{ZnO}$. The confinement is explained by the very localized nature of VIGS in real space leading to the formation of accumulation layers at the $\mathrm{ZnO}(000 \overline{1})$ surface, which can even show quantized electron sub-band states. ${ }^{36,44}$

Upon annealing, a thin $\mathrm{MnO}$ film forms on top of the surface of $\mathrm{ZnO}$. As seen in Figure 5a, the valence band edge appears at a binding energy roughly $1 \mathrm{eV}$ above that of $\mathrm{ZnO}$. According to the literature, ${ }^{45}$ this feature can be attributed to hybrid O $2 \mathrm{p}-\mathrm{Mn} 3 \mathrm{~d}$ antibonding states which are predicted to be the highest occupied states in $\mathrm{MnO}$. In the present work, the valence band edge of $\mathrm{MnO}$ is located around $\sim 1.6 \mathrm{eV}$ below the Fermi edge, which is also $0.8 \mathrm{eV}$ further away than typical valence band onset values reported in the literature. ${ }^{46}$ As seen in Figure $5 a$ and $b$, the $\mathrm{ZnO}$ bands moves $0.3 \mathrm{eV}$ closer to the Fermi level. In the present case, the band bending is seen as a displacement of $\mathrm{Zn}$ and $\mathrm{O}$ related XPS spectral features. No more bulk (flat band) related feature is seen in the spectra related to $\mathrm{ZnO}$. Owing to the respective band aps and electroaffinities from $\mathrm{MnO}$ and $\mathrm{ZnO},{ }^{47} \mathrm{a}$ band discontinuity appears at the interface between the two oxides (Figure $5 \mathrm{c}$ ). As the Fermi level moves away from the $\mathrm{CNL}$ of $\mathrm{ZnO}$, we must assume that the charge transfer between $\mathrm{MnO}$ and $\mathrm{ZnO}$ is insufficient to reach a situation where the $\mathrm{CNL}$ of both $\mathrm{ZnO}$ and $\mathrm{MnO}$ coincides with the Fermi level. As illustrated in Figure 5c (right panel), this means that, upon Mn oxidation, the $\mathrm{ZnO}$ substrate underneath is no more terminated by a highly conductive layer and hence band bending extends much further into the bulk of $\mathrm{ZnO}$.
Finally, upon dilution, the local concentration of $\mathrm{Mn}$ drops down to a few percent. The band structure of $(\mathrm{Zn}, \mathrm{Mn}) \mathrm{O}$ becomes very close to that of $\mathrm{ZnO}$. We also observe that $\mathrm{Mn}$ does not dope $\mathrm{ZnO}$, or in other words that the incorporated $\mathrm{Mn}$ in a 2+ state does not modify the position of the Fermi level within the band gap of $\mathrm{ZnO}$.

\section{CONCLUSIONS}

A detailed analysis of the physical processes and chemical reactions (charge transfer, formation of a two-dimensional $\mathrm{MnO}$ layer, and $\mathrm{Mn}$ diffusion occurring at the $\mathrm{Mn} / \mathrm{ZnO}$ interface) has been provided thanks to the bulk-sensitivity of HAXPES. Charge transfer occurs between the metallic $\mathrm{Mn}$ film and the $\mathrm{ZnO}$ surface and causes the downward band bending of the $\mathrm{ZnO}$ valence band in the interfacial region. Oxidation and diffusion of a thin $\mathrm{Mn}$ film grown onto $\mathrm{ZnO}(000 \overline{1})$ upon annealing leads to various side effects which may play a crucial role in nanometerscale devices. In particular, we identified a modification of the band bending and conductivity at the $\mathrm{Mn} / \mathrm{ZnO}$ interface upon annealing. It was found that $\mathrm{Mn}$ diffuses via substitution in $\mathrm{ZnO}$, and the related diffusion coefficient was experimentally determined $\left(D t \sim 1.4 \times 10^{-19} \mathrm{~m}^{2} / \mathrm{s}\right)$.

\section{AUTHOR INFORMATION}

\section{Corresponding Author}

*E-mail: mugumaom@fundp.ac.be.; mugcubaka@gmail.com.

\section{ACKNOWLEDGMENT}

We would like to thank Sebastian Thiess, Wolfgang Drube, and Heiko Schulz-Ritter for excellent technical and experimental support at beamline BW2 of the Deutsches Elektronen-Synchrotron (DESY). We thank Cathérine Moisson (NOVASiC) for MCP of and providing the $\mathrm{ZnO}$ single crystals. This work was supported by CERUNA-University of Namur, Belgian National Fund for Scientific Research (F.S.R.-FNRS), DESY and the European Commission under contract RII3-CT 2004-506008 (IA-SFS). 


\section{REFERENCES}

(1) Fadley, C. S. Surf. Interface Anal. 2008, 40, 1579-1605.

(2) Drube, W. Nucl. Instrum. Methods Phys. Res., Sect. A 2005, 547, 87-97.

(3) Theodoropoulou, N.; Misra, V.; Philip, J.; LeClair, P.; Berera, G. P.; Moodera, J. S.; Satpati, B.; Som, T. J. Magn. Magn. Mater. 2006, 300, 407-411.

(4) Ueda, K.; Tabata, H.; Kawai, T. Appl. Phys. Lett. 2001, 79, 988-990.

(5) Pan, F.; Song, C.; Liu, X. J.; Yang, Y. C.; Zeng, F. Mater. Sci. Eng., $R$ 2008, 62, 1-35.

(6) Coey, J. M. D.; Chambers, S. A. MRS Bull. 2008, 33, 1053-1058.

(7) Droubay, T. C.; Keavney, D. J.; Kaspar, T. C.; Heald, S. M.; Wang, C. M.; Johnson, C. A.; Whitaker, K. M.; Gamelin, D. R.; Chambers, S. A. Phys. Rev. B 2009, 79, 155203, 9 pp.

(8) Zou, C. W.; Wu, Y. Y.; Sun, B.; Gao, W.; Xu, P. S. Surf. Interface Anal. 2007, 39, 865-870.

(9) Guziewicz, E.; Kopalko, K.; Sadowski, J.; Guziewicz, M.; Golacki, Z.; Kanski, J.; Ilver, L. Phys. Scr., T 2005, 115, 541-544.

(10) Grossner, U.; Gabrielsen, S.; Børseth, T. M; Grillenberger, J.; Kuznetsov, A. Yu.; Svensson, B. G. Appl. Phys. Lett. 2004, 85, 22592261.

(11) Wang, X. D.; Summers, C. J.; Wang, Z. L. Appl. Phys. Lett. 2005, $86,013111,3 \mathrm{pp}$.

(12) Campbell, C. T. Surf. Sci. Rep. 1997, 27, 1-111.

(13) Sumiya, M.; Lozach, M.; Matsuki, N.; Ito, S.; Ohashi, N.; Sakoda, K.; Yoshikawa, H.; Ueda, S.; Kobayashi, K. Phys. Status Solidi C 2010, 7, 1903-1905.

(14) Oku, M.; Hirokawa, K.; Ikeda, S. J. Electron Spectrosc. Relat. Phenom. 1975, 7, 465-473.

(15) van Elp, J.; Potze, R. H.; Eskes, H.; Berger, R.; Sawatzky, G. A. Phys. Rev. B 1991, 44, 1530-1537.

(16) Allegretti, F.; Franchini, C.; Bayer, V.; Leitner, M.; Parteder, G.; Xu, B.; Fleming, A.; Ramsey, M. G.; Podloucky, R.; Surnev, S.; Netzer, F. P. Phys. Rev. B 2007, 75, 224120, 8 pp.

(17) Oku, M.; Wagatsuma, K.; Konishi, T. J. Electron Spectrosc. Relat. Phenom. 1999, 98-99, 277-285.

(18) Mizokawa, T.; Nambu, T.; Fujimori, A.; Fukumura, T.; Kawasaki, M. Phys. Rev. B 2002, 65, 085209, 8 pp.

(19) Parmigiani, F.; Sangaletti, L. J. Electron Spectrosc. Relat. Phenom. 1999, 98-99, 287-302.

(20) Müller, F.; de Masi, R.; Reinicke, D.; Steiner, P.; Hüfner, S.; Stöwe, K. Surf. Sci. 2002, 520, 158-172.

(21) Mugumaoderha, M. C.; Sporken, R.; Ghijsen, J.; de Groot, F. M. F.; Dumont, J. A. J. Phys. Chem. C, submitted.

(22) Jablonski, A.; Powell, C. J. J. Electron Spectrosc. Relat. Phenom. 1999, 100, 137-160.

(23) Anisimov, V. I.; Korotin, M. A.; Kurmaev, E. Z. J. Phys.: Condens. Matter 1990, 2, 3973-3987.

(24) Tanuma, S.; Powell, C. J.; Penn, D. R. Surf. Interface Anal. 2003, $35,268-275$.

(25) Baümer, M.; Freund, H. J. Prog. Surf. Sci. 1999, 61, 127-198.

(26) Schrön, A.; Rödl, C.; Bechstedt, F. Phys. Rev. B 2010, 82, 165109, $12 \mathrm{pp}$.

(27) Dumont, J.; Couet, S.; Seldrum, T.; Moisson, C.; Turover, D.; Sporken, R. J. Vac. Sci. Technol., B 2006, 24, 2124-2131.

(28) Dumont, J.; Mugumaoderha, M. C.; Seldrum, T.; Frising, F.; Moisson, C.; Turover, D.; Sporken, R. J. Vac. Sci. Technol., B 2007, $25,1536-1541$.

(29) Kleinlein, F. W.; Helbig, R. Z. Phys. A 1974, 266, 201-207.

(30) Koskelo, O.; Räisänen, J.; Tuomisto, F.; Eversheim, D.; Grasza, K.; Mycielski, A. Thin Solid Films 2010, 518, 3894-3897.

(31) Mönch, W. Appl. Surf. Sci. 1997, 117-118, 380-387.

(32) King, P. D. C.; Veal, T. D.; Jefferson, P. H.; Zúñiga-Pérez, J.; Muñoz-Sanjosé, V.; McConville, C. F. Phys. Rev. B 2009, 79, 035203, 5 pp.

(33) Walukiewicz, W. Phys. B 2001, 302-303, 123-134.

(34) Ashrafi, A. Surf. Sci. 2010, 604, L63-L66.
(35) Girard, R. T.; Tjernberg, O.; Chiaia, G.; Söderholm, S.; Karlsson, U. O.; Wigren, C.; Nylén, H.; Lindau, I. Surf. Sci. 1997, 373, 409-417.

(36) Piper, L. F. J.; Preston, A. R. H.; Fedorov, A.; Cho, S. W.; DeMasi, A.; Smith, K. E. Phys. Rev. B 2010, 81, 233305, 4 pp.

(37) Lavrov, E. V. Phys. B 2009, 404, 5075-5079.

(38) Janotti, A.; Van de Walle, C. G. Rep. Prog. Phys. 2009, 72, 126501, 29 pp.

(39) Kunat, M.; Gil Girol, S.; Becker, T.; Burghaus, U.; Wöll, Ch. Phys. Rev. B 2002, 66, 081402, 8 pp.

(40) Ip, K.; Overberg, M. E.; Heo, Y. W.; Norton, D. P.; Pearton, S. J.; Stutz, C. E.; Kucheyev, S. O.; Jagadish, C.; Williams, J. S.; Luo, B.; Ren, F.; Look, D. C.; Zavada, J. M. Solid-State Electron. 2003, 47, 22552259.

(41) Bang, J.; Chang, K. J. J. Korean Phys. Soc. 2009, 55, 98-102.

(42) Weber, M. H.; Lynn, K. G. J. Phys.: Conf. Ser. 2011, 262, 012063, 6 pp.

(43) Nickel, N. H. Superlattices Microstruct. 2007, 42, 3-7.

(44) Dumont, J.; Hackens, B.; Faniel, S.; Mouthuy, P. O.; Sporken, R.; Melinte, S. Appl. Phys. Lett. 2009, 95, 132102, 3 pp.

(45) Massidda, S.; Continenza, A.; Posternak, M.; Baldereschi, A. Phys. Rev. Lett. 1995, 74, 2323-2326.

(46) Nagel, M.; Biswas, I.; Nagel, P.; Pellegrin, E.; Schuppler, S.; Peisert, H.; Chassé, T. Phys. Rev. B 2007, 75, 195426, 6 pp.

(47) Xu, Y.; Schoonen, M. A. A. Am. Mineral. 2000, 85, 543-556. 